\title{
2. EXPLORING THE TENSION AND SYNERGIES BETWEEN SCIENCE AND TECHNOLOGY IN SCIENCE EDUCATION
}

\begin{abstract}
INTRODUCTION
This chapter explores the way in which technology has been introduced through and by science educators in Australasia in the last 25 years. A number of themes have arisen in this time from using technology to engage students in science, exploring the impact of science on society through technology, considerations of the nature of technology in relation to science, and the exploration and development of technology as a subject in its own right. In this process student and teacher perceptions of technology were explored, as well as teacher change and the influence of teacher/ subject culture through to sustained classroom research and school change and the way in which the introduction of a new subject like technology can influence our thinking around science. In the early 1980s technology was introduced in terms of science, technology and society as well as playing a role of providing applications or examples of science in action. The underlying assumptions were that technology was applied science. In the late 1980s debates began to arise around the nature of technology, its place in the curriculum and its relationship to science. In the mid to late 1990s until 2007 we have seen a distinct move to examine technology in the classroom and to use the lessons from science to explore the teaching, learning and assessment of technology. Throughout this process research in science education has informed our ideas about technology, and our exploration of technology with teachers and students in the classroom has influenced our approaches to science education, in curriculum development, teacher development, classroom research, student learning and wider school reforms.

In exploring the relation and tension between science and technology in Australasia I have not attempted to review all technology research and development in that time but rather examine the development of technology where people have been involved in both science and technology education. A review of the development of technology education as an area of research and development in its own right in Australasia is for another publication.
\end{abstract}

\section{SCIENCE, TECHNOLOGY AND SOCIETY}

The 1980s in Australia and New Zealand saw an attempt to include the theme of science, technology and society (STS) in the research and curriculum agenda. Fensham, (1987), identifies eleven dimensions or aspects of STS learning. These 
are: the relation between science and technology; technocratic/democratic decision making; scientists and socio-scientific decisions; science/technology and social problems; influence of society on science/technology; social responsibility of scientists; motivation of scientists; scientists and their personal traits; women in science and technology; social nature of scientific knowledge; and characteristics of scientific knowledge (scientific methods, models, classification schemes, tentativeness). The STS movement began due to a combination of factors, including the growing concern in the 1960s that science education had become divorced both from its social origins, and from the social implications of scientific endeavour. This was often expressed as the "social relevance of science" (Fensham, 1987, p. 1). There was also a push for science education to become more technology related. This early shift in increasing the relevance of science through being more technology related was used by Jones (1982) to explore technological applications of physics as a means of providing real-world examples of physics concepts. This approach was limited to a greater focus in technology but did not pick up the social aspects. However, this notion of expanding the technological focus within science allowed for exploration of technology to expand problem solving in science.

Corrigan (1999) explored the consequences for teaching and learning of the introduction of STS perspectives into a senior secondary chemistry curriculum in Victoria. Her research explored the ways in which the introduction of social aspects of chemistry influenced how teachers and students perceived school chemistry. This also included exploring the purposes for including technological and industrial tasks in chemistry curriculum and the way these purposes were perceived by teachers and students.

The introduction of biotechnology as an area of research and development, including curriculum development provided a means to develop a much more research focused agenda around science, technology and society. Advances in biotechnology have social, political, economic and wider cultural implications and present society with ethical issues and dilemmas which require informed citizens capable of contributing to public debate. An improved understanding of socioscientific issues amongst young people will help to ensure they have an informed, defensible view and that they understand, for example, the rationale for national initiatives to combat environmental issues involving genetically modified organisms (Dawson, 2003).

Part of the reason for including social and technological issues is to introduce values and ethics into science. Conner (2003) has provided an on-going commentary and analysis of the efficacy of bioethics teaching in New Zealand, with a focus on the implementation of such programs in senior biology classes. Conner's view that students need to develop critical thinking skills when working through biotechnological issues and her recent research in this area, provides some useful ideas for developing this component of biotechnology education. With respect to learning about bioethics, Conner and Gunstone (2004) propose that better understanding of bioethical issues will occur when students are able to re-evaluate their personal ideas and beliefs and its relevance to the issue in question; for example, Conner's analysis of the efficacy of 16 final year high school biology students documenting their conscious knowledge of learning when they wrote essays about cancer. 
Recent studies of the attitudes of high school students to biotechnology found that the ethical problems generated by biotechnology interested them but that many students are unable to distinguish between current and potential uses of biotechnology (Dawson \& Schibeci, 2003). Student-centred inquiry approaches to bioethics education that build on students' existing or prior knowledge are therefore desirable (Conner, 2005). In such approaches, the teacher's role is facilitative and includes assisting students to examine and evaluate controversial issues critically, from multiple perspectives, using a good decision-making model (Conner, 2003, 2007).

It seems clear that students need opportunities to develop, reflect on, and justify their bioethical values (Dawson \& Taylor, 1999). Dawson (2003) identifies the multiple skills involved in students' ethical decision-making: ethical sensitivity (in identifying the dilemma); ethical reasoning (identifying and weighing up arguments for and against different decisions); and ethical justification (reaching and justifying a decision). While approaches derived from STS programs; for example, case studies, structured debates, oral presentations and scenarios, can be adapted to promote student questioning and decision-making about societal issues, many of these do not delve deeply into the social and ethical aspects (Conner, 2002).

Research has examined social issues in science education but there has not been a large amount of research on STS as a sustained research agenda in Australasia. Part of the reason is that those involved in the early days of STS and similar areas focused their attention on technology as a developing curriculum area in the 1990s and beyond.

\section{PERCEPTIONS OF TECHNOLOGY BY SCIENCE TEACHERS}

As technology was being increasingly linked with science education and as an area of study in its own right, concern was raised as to what were teachers' and also students' perceptions of technology. Studies were undertaken on perceptions of technology but this section focuses on science teachers' perceptions of technology.

In the study conducted by Jones and Carr (1992) on teachers' perceptions of technology and technology education they found that all the science teachers who were interviewed saw technology education in terms of applications of science. In terms of teaching, technology was perceived to be a vehicle for teaching science and often something extra to the conceptual development in science. There was concern expressed about non-science teachers incorporating the scientific aspects of technology into their lessons. At the time of the study in both the primary and intermediate school setting teachers were trying to integrate computers into their classrooms. In the primary school there was one computer per class and at the intermediate school the computers were located in a resource area. Many of the teachers at the primary and intermediate school viewed technology in terms of computers. For these teachers technology meant using computers or other technology to solve problems. Although they might be aware of the range of technology they tended to focus on computing. For example, as stated by one teacher, not using pen or paper but using computers to solve problems. Teachers also mentioned problem solving in relation to finding out how things work. When talking about technology, teachers have mentioned problem-solving both in the context of using computers 
and finding out how things work. Technology is seen as a mechanism for solving a problem or as a vehicle for approaching a particular type of problem solving; that is, finding out how things work, particularly in science at the secondary school level.

Moreland (1998) reported that although the teachers stated they needed to learn more about the teaching of technology, they felt they had enough skills and understanding to be teaching technology and could do it in the classroom. One teacher with a science strength set the students applied science tasks (design a hot balloon after studying flight). Technological principles were not involved. The criteria were in terms of why things happened and a narrow focus of outcomes. Northover (1997) noted that all the science teachers she worked with viewed technology as being applied science and technology as skills and skill development. The teachers went for minimal change and added technology into existing programs rather than developing new ones or new learning outcomes. She found that these teachers generally expressed an interest in technology education and commented on the motivational aspects of technological activities. Teachers often saw changes in their perceptions of technology and technology education as a means of better understanding the curriculum document. However they did not see the import of the development of a coherent technological knowledge base to their own learning and teaching practice. The dominant science sub-culture in schools proved to be a powerful conservative influence. Teachers who evidenced a changed view of technology and biotechnology at earlier stages throughout the teachers' development by the end had often reverted to the perspective held initially. In fact, where teachers did make changes to their perceptions initially the cognitive dissonance set up by the disparity between their views and their practice was often resolved by reverting to a previously held view.

The strategies developed by the teachers in their classrooms when implementing technological activities were often positioned within that particular teacher's teaching and subject sub-culture. These sub-cultures are consistent and often strongly held. The sub-cultures had a direct influence on the way the teachers structured the lessons and developed classroom strategies. Teachers developed strategies to allow for learning outcomes that were often more closely related to their particular subject sub-culture than to technological outcomes; for example, science and language. Teachers entering areas of uncertainty in their planned activities often reverted to their traditional teaching and subject sub-culture. Their views of assessment, their expectations of the students, and their views of learning, influenced possible learning outcomes identified by teachers in technological activities. When students were carrying out technological activities teachers often reverted to learning areas they were comfortable with for identifying possible learning outcomes rather than technological outcomes. It would appear that the introduction of a "new" learning area in schools, such as technology, is problematic. Teachers' existing sub-cultures in terms of teaching and learning, subject area, and school, in association with their concepts of technology, influence the development of classroom environment and strategies, and consequent student activities. 
In an attempt to increase the relevance and authenticity of science the introduction of technological applications were seen as a means of achieving this. Research was carried out by Jones (1988) into the effect of introducing technological applications on students' concepts of physics. Using such applications as earthquake monitoring systems and baby breathing monitors, it was found that the students indicated that these technological applications helped them to remember scientific concepts involved. No change was recorded, however, if the applications were used as an add on either at the beginning or end of a lesson. The students also commented that the use of such technological contexts also provided frameworks for the construction of further scientific concepts to those specifically targeted. Another important outcome from this research was the significant increase in the students' level of confidence, interest and enjoyment in science generally. This was a factor noted by both the students and their teachers.

Research in science education that explored the use of technological applications for the teaching of science, suggests such contexts do have a positive effect on students learning of scientific principles and concepts (e.g., Jones \& Kirk, 1990; Rodrigues, 1993). Care must be taken however, that the technological context used is appropriate to the students and the scientific content, and that it is presented as an integral part of the learning experience rather than an add on for the sake of sparking interest. For example, Jones and Kirk (1990) qualify their statement regarding how a technological focus enhances the learning of science concepts for most students by stating the need for the context to be linked to suitable teaching sequences and the context integrated into the lesson sequence rather than being used for illustrative purposes.

Rodrigues's (1993), research included exploring the role and effect of context on female students' learning of oxidation and reduction. Using such technological applications as breathalysers, and hair perming and colouring systems as contexts, Rodrigues found that not only did students become more interested in the scientific concepts of oxidations and reduction, but they also showed a large increase in the number and quality of classroom interactions both with each other and the teacher. These interactions took many forms, including direct questioning and discussion centred on both the functions and use of the application and the scientific concepts involved (Rodrigues, 1993). The researcher's observations were that the students appeared to take "control of their learning” (Rodrigues \& Bell, 1995, p. 807) and teacher, student, and researcher statements all appeared to suggest that the students experienced an increased conceptual understanding of redox reactions.

\section{TECHNOLOGICAL PROBLEM SOLVING IN SCIENCE CLASSROOMS}

There have been many attempts to introduce technological problem solving in science classrooms. However, extensive classroom observations undertaken in science classrooms when technology problems have been introduced have shown that the science classroom culture and student expectations appeared to influence strongly the way in which students carried out their technological activities (Jones, 
1994). The students in the science classrooms involved in this research enjoyed carrying-out technological problem solving and their teachers reported considerable enthusiasm for these activities. The main conclusion was that science classroom cultures needed to be understood as greatly affecting performance in technological problem solving. Students' expectations of classroom practice were influenced by subject subcultures. For example, throughout the technological activity which was situated in a science classroom and timetabled slot, the students played by the "rules" of the science classroom. Their perceptions of the activities they were to be involved in were significantly affected by prior concepts of "project” work in science. The focus throughout the unit was therefore primarily in terms of collecting information to present to the class. Students often did not continue with explorations of wider social issues as they did not see this as relevant to their notions of science. Jones and Carr (1993) indicated that the majority of students in the science classroom limited themselves to using science resources even though they had been encouraged by the teacher to use outside resources. The solutions that the students sought were often in terms traditional solutions utilised in their prior experiences of the science classroom. When questioned, these students often stated clearly that they could have done more towards solving their problems, but they consciously limited themselves to what they considered was appropriate within the science classroom. Students often stated that they learnt scientific concepts when undertaking the technological activity, and appeared to view this as the legitimate learning outcome for the activity.

Forret (1997) investigated the early learning of electronics. He used problem solving and contextual approaches to introduce electronics to students. He found that students had an interest in electronics, had enhanced practical competence in constructing circuits and enhanced problem solving. Like Forret, Hampson (2000) noted that students developed greater problem solving skills when engaged in design activities. Ginns, Norton and McRobbie (2005) highlighted that science learning outcomes can be identified by some students in technological activities. These learning outcomes were related to work that the students had covered earlier in the year. However, Norton, McRobbie and Ginns (2007) noted that opportunities for extracting science principles from technological activities have not been maximized. Norton et al. (2007) indicate that introducing technology in science allows students to think for themselves, apply logical thinking, be creative and allow for student autonomy.

When technological problem solving and design activities are introduced into science classrooms, students are interested, enjoy the experience and in many cases learn some scientific concepts (see Roth, Tobin, \& Ritchie, 2001). There is very little evidence of transfer of scientific knowledge to technological solutions and little understanding of the processes involved. The technological process adopted by the students is somewhat fragmented and appropriate solutions are not forthcoming. The culture of learning in science classrooms does not appear to lend itself to helping students develop technological capability or intend technological literacy. The introduction of technological problem solving into science classrooms needs careful consideration if technological literacy is a desired learning outcome in science. 
The late 1980s and 1990s saw the greater inclusion of technology as an area of study in Australian and New Zealand science curricula. Internationally there was also an emphasis on the inclusion of technology as a vehicle for the learning of science. However generally science curricula portray a narrow view of technology. Such a narrow view of technology relies on a concept of technology as very much focused on applied science. As has been stated elsewhere (Bell, Jones, \& Carr, 1995), the treatment of technology as embedded in science is cause for concern as it means that other forms of knowledge, including technological knowledge, which are all essential for technology, are not apparent. It also excludes many technological innovations and developments that have no direct links to science as a discipline. For example in the early levels of the science curriculum in New Zealand the primary reason for introducing technology was for the purpose of clarifying and demonstrating the scientific principle. At higher levels of the curriculum the focus shifted to that of investigating in a very general way the relationship between science and technology. Emphasis was now placed on acknowledging and understanding how technological advances have aided or in fact enabled, the development, or major rethinking of scientific ideas. The way in which scientific principles have provided crucial knowledge for technological development and advance is also highlighted, for example, the development and uses of genetic finger printing. When there was a focus on learning how technological artifacts function, this was in terms of scientific principles only, ignoring technological and other knowledge bases crucial to the successful functioning of technological artifacts, systems and environments. The principles behind technological innovation are perceived to be only those belonging to science. There was some opportunity within this aim to see how technological developments impact on scientific knowledge, and vice versa. This opportunity is constrained to those technologies fitting the applied science notions of technological developments. There is also opportunity for the exploration of the effect of technological development of society, however it is specifically stated that the means of such an evaluation should be through the application of scientific knowledge.

France (2007) has taken a leading role in biotechnology education in Australasia. The development of a scientifically and technologically literate citizen has been the goal of educators and biotechnology provides a fruitful context for this. In most international curricula biotechnology appears within senior science and biology and correspondingly its classroom implementation provides examples of technology as applied science. However, this narrow focus of biotechnology may limit the exploration of socio-political or ethical dimensions of biotechnology classroom programs, and provides limited opportunities for students to develop rich scientific and technological literacies.

France and Bolstad (2004) found that the position of biotechnology in science curricula internationally tended to place it within an applied science (Technology as applied science) framework. An expression of such applied science examples are microbiological processes being identified within human health and disease, examples to illustrate anaerobic respiration (bread and ginger beer making) and the 
application of microbial degradation in waste disposal and composting. As they note what is missing from most of the curricula are opportunities for discussion of socio-political issues as well as values inherent in technological processes. This positioning of biotechnology in this way means that technology itself is underplayed and also the chance for students to develop a greater understanding of the relationship between science and technology and the values inherent in this.

In an examination of science curricula, biotechnology tends to be seen at the higher levels of the biology curriculum and mainly to do with genetic manipulation (France \& Bolstad, 2004). Biotechnology in terms of GM debates can put its inclusion in the curriculum more towards the discussion of controversial issues rather than consideration of a broader understanding of biotechnology in its wider context. The aligning of biotechnology only with controversial issues also means that students may develop a distorted view of biotechnology rather than seeing it in its fuller context. This representation of technology in science only shows a relationship in terms of science to technology as application and this represents a view of technology as being applied science. It also tends to reflect a deterministic view of technology and in fact science for that matter.

\section{DEFINING TECHNOLOGY IN RELATIONSHIP TO SCIENCE}

With the introduction of technology into curricula and research there was much rhetoric internationally about the relationship between science and technology in the early 1990s. People use technology to expand their possibilities, to intervene in the world through the development of products, systems and environments. To do this, intellectual and practical resources are applied. Technology includes control, food, communications, structural, bio-related, materials, and creative design processes. From a research and development perspective, Gardner's (1994) review on science and technology had a significant influence. He argued that the relationship between science and technology could be seen in four ways:

- Technology as applied science;

- Science and technology as independent communities;

- Technology as giving rise to scientific understanding;

- Science and technology as equal and interacting communities.

Technology can be utilised in a variety of ways in science education, however in doing so it is important to have a clear concept both of the nature of science and the nature of technology. Too often in the past a limited view of technology in science has limited both the learning of science and the learning about technology. When technology is viewed as applied science it is assumed that there is a linear relationship in which science generates technology, and when this view is held the story of a technological development is projected through the science lens (Gardner, 1995). Gardner's description of technological fruits falling from scientific trees (Gardner, 1994) is a common representation of the scientific applications of biotechnological knowledge; for example, the utilisation of penicillin from Sir Alexander Fleming's discovery of the action of Penicillium moulds on bacteria. In fact such a relationship was far from linear and involved many people. Even though such a linear relationship can be discredited in any science/technology 
history, this simple "technology-as-applied science" relationship is still exploited in science education, since examples like the discovery of penicillin can provide fruitful illustrative examples of scientific processes. However the reality of modern science is that strategic research occurs in teams with a focus on the functional aspects of science and technology as it relates to human welfare, economic development, social progress and the quality of life. France (2007) explored biotechnology from Gardner's framework in a thorough literature review of biotechnology education and its place in the curriculum. France concludes that biotechnology is a modern science which provides a context to show teachers how teams of scientists, technologists and social scientists work together.

\section{INTEGRATION OF SCIENCE AND TECHNOLOGY}

Venville, Wallace, Rennie, and Malone (2002) explored in detail notions of curriculum integration and what it might mean from both a theoretical and practical perspective. They explored the nature of integration and how it is represented in the school environment. They also examined why integration should be considered, and focused on student engagement and whether integration enhances learning in science. Venville et al. (2002) highlight several studies that show that an authentic curriculum, related to student needs and interests and to the world outside of school, results in increased participation and engagement and reduced alienation. In their paper they highlight competitions such as the Science Talent Search provide opportunities for the integration between science, mathematics and technology. They indicated that subjects such as science, when placed within an integrated curriculum that is based on content, is difficult to assess and relatively open to debate.

Venville et al. (2002) provide an example of integrated practice involving the use of technology-based projects. High School students worked on a technology project for 10 to 12 weeks that included technology, science and mathematics research components. An example of a technology project brief was to "design and produce an electric powered vehicle that can climb a steeper gradient on the standard test track than anyone else's.” The technology aspect investigated traction options, materials and construction techniques, motor mounting options and power transmission systems. The science aspect investigated friction, gears and pulleys, torque and power transfer and how scientific trials influenced their choice of traction, gearing and drive options.

This is an area for further research but cognizance needs to be taken of the way science as a high status subject, and teachers' and students' perceptions of and understanding of the relationship between science and technology, will influence the outcomes in the classroom.

\section{CONCLUSION}

This chapter has considered ways in which technology has been included in science education research and development. A broad notion of technology was taken in terms of people using technology to expand their possibilities, to intervene in the world through the development of products, systems and environments. To 
do this, intellectual and practical resources are applied. Technology includes control, food, communications, structural, bio-related, materials, and creative design processes. From a research and development perspective this did not include the introduction of Information and Communication Technologies in science education.

The rationale for the introduction of technology in science has centred on an attempt to increase the relevance and authenticity of science to students. There is evidence that when this is introduced in an appropriate way that there is increased enjoyment and even improvement for some students in science achievement. Technology with science education has essentially been portrayed as applied science and limited aspects of technology have been included. Technology was essentially perceived as applied science and this influenced the way it was introduced to the classroom. The introduction of technology and also social aspects allowed for values and ethics to be introduced into the science classroom particularly in relation to biotechnology in biology classes. The introduction of technology into science classes has seen technology dominated by the science subculture. When technological applications were introduced in a themed approach rather than an add on then students were more likely to engage in science, enjoy it more and achieve both in science and technology. In the science curriculum technology has been essentially introduced as applied science although at the higher levels of the curriculum technology is seen as advancing science but the focus was on the direct links with science rather social or technological principles. The potential of technology to make a difference in the teaching and learning of science has probably not reached the potential we thought it might when we began exploring its introduction 25 years ago. The rise of technology education research as an area in its own right may have limited the further research into possible connections between science and technology.

\section{REFERENCES}

Bell, B., Jones A., \& Carr, M. (1995). The development of the recent national New Zealand science curriculum. Studies in Science Education, 26, 73-105.

Conner, L. (2003). The importance of developing critical thinking in issues education. New Zealand Biotechnology Association Journal, 56, 58-71.

Conner, L. (2007). Cueing metacognition to improve researching and essay writing in a final year high school biology class. Research in Science Education, 37, 1-16.

Conner, L., \& Gunstone, R. F. (2004). Conscious knowledge of learning: Accessing learning strategies in a final year high school biology class. International Journal of Science Education, 26, 14271443.

Corrigan, D. J. (1999). Technology and industry links with chemistry curricula. Unpublished PhD Thesis, Monash University, Melbourne, Victoria, Australia.

Dawson, V. (2003). Effect of a forensic DNA testing module on adolescents' ethical decision-making abilities. Australian Science Teachers' Journal, 49, 12-17.

Dawson, V., \& Schibeci, R. (2003). Western Australian high school students' attitudes towards biotechnology processes. Journal of Biological Education, 38, 7-14.

Dawson, V., \& Taylor, P. (1999). Teaching bioethics in science: Does it make a difference? Australian Science Teachers' Journal, 45, 59-64.

Fensham, P. J. (1988). Approaches to the teaching of STS in science education. International Journal of Science Education, 10, 346-356. 
Forret, A. (1997). Learning electronics: an accessible introduction. Unpublished PhD Thesis, University of Waikato, Hamilton, New Zealand.

France, B. (2007). Location, location, location: Positioning biotechnology education for the 21st century. Studies in Science Education, 43, 88-122.

France, B., \& Bolstad, R. (2004). Enhancing biotechnology education in New Zealand schools. A literature review of approaches to raise awareness and enhance biotechnology in schools. Wellington, NZ: New Zealand Council for Educational Research.

Gardner, P. (1994). Representations of the relationship between science and technology in the curriculum. Studies in Science Education, 24, 1-28.

Gardner, P. (1995). The relationship between science and technology: Some historical and philosophical reflections. Part II. International Journal of Technology and Design Education, 5, 1-33.

Ginns, I. A., Norton, S. J., McRobbie, C. J., \& Davis, R. S. (2007). Can twenty years of technology education assist "grass roots" syllabus implementation? International Journal of Technology and Design Education, 17, 197-215.

Hampson, B. (2000). The strength of ideas in construction projects: A teacher's window of perception. Research in Science Education, 30, 269-287.

Jones, A. (1982). Physics at work in New Zealand. Auckland: Science Centre.

Jones, A. (1988). The introduction of technological application in senior physics. Unpublished $\mathrm{PhD}$ Thesis, University of Waikato, Hamilton, New Zealand.

Jones, A. (1994). Technological problem solving in two science classrooms. Research in Science Education, 24, 182-190.

Jones, A., \& Carr, M. (1993). Analysis of student technological capability. Centre for Science and Mathematics Education Research, University of Waikato, Hamilton.

Jones, A., \& Kirk C. (1990). Introducing technological applications into the physics classroom. Help or hindrance to learning? International Journal of Science Education, 12, 481-490.

Moreland, J. (1998). Technology education teacher development: the importance of experiences in technological practice. Unpublished Master's Thesis, University of Waikato, Hamilton, New Zealand.

Northover, B. (1997). Teacher development in biotechnology: teachers' perceptions and practice. Unpublished Master's Thesis, University of Waikato, Hamilton, New Zealand.

Norton, S. J., Mcrobbie, C. J., \& Ginns, I. S. (2007). Problem solving in a middle school robotics design classroom. Research in Science Education, 37, 261-277.

Rodrigues, S., (1993). The role and effect of context on learning six form oxidation and reduction by female students. Unpublished PhD Thesis, University of Waikato, Hamilton, New Zealand.

Rodrigues, S., \& Bell, B. (1995). Chemically speaking: A description of student-teacher talk during chemistry lessons using and building on students' experiences. International Journal of Science Education, 17, 797-809.

Roth, W. M., Tobin, K., \& Ritchie, S. (2001). Re/Constructing elementary science. New York: Peter Lang.

Venville, G., Wallace, J., Rennie, L., \& Malone, J. (2002). Curriculum integration: Eroding the high ground of science as a school subject? Studies in Science Education, 37, 43-84.

\section{Alister Jones \\ School of Education \\ University of Waikato}

